\title{
Recurrent wheezing in infants and preschool children - risk factors that influence the severity of acute episodes
}

\section{Wheezing-ul recurent la sugar şi copil - factori de risc ce influențează severitatea episoadelor acute}

\author{
Alexandru-Ioan ULMEANU ${ }^{1,2}$, Andreea Maria VLAD ${ }^{1}$, \\ Carmen ZĂPUCIOIU ${ }^{1,2}$, Coriolan ULMEANU ${ }^{1,2}$ \\ ${ }^{1}$ SCUC „Grigore Alexandrescu“, București, România \\ Universitatea de Medicină şi Farmacie „Carol Davila“, București, România
}

\begin{abstract}
REZUMAT
Wheezing-ul recurent este o afecțiune foarte frecvent întâlnită în grupa de vârstă 0-6 ani. Mai mulți factori de risc sunt asociați acestuia, atât factori genetici, cât și factori de mediu prenatali sau postnatali. Este important de evaluat în ce măsură acești factori sunt implicați în apariția wheezing-ului recurent, dar și cum influențează ei evoluția bolii.

Obiective. Obiectivul studiului a fost de a evalua prezența factorilor de risc ce influențează severitatea episoadelor acute de wheezing la copii cu wheezing recurent.

Material și metodă. Am realizat un studiu observațional, prospectiv, ce a inclus 40 de copii, pentru a dovedi existența unora asocieri epidemiologice între anumiți factori de risc și wheezing-ul recurent în rândul copiilor cu vârsta cuprinsă între 0 şi 6 ani.

Rezultate. Vârsta medie a fost de aproximativ 22 de luni, vârsta minimă fiind de 3 luni, iar cea maxima de 67 de luni. Dintre cei 40 de pacienți, 42,5\% $(n=17)$ au prezentat semne de insuficiență respiratorie acută la internare, aceștia fiind pacienții cu o severitate crescută a episodului acut de wheezing.

Majoritatea copiilor au fost născuți la termen, fără suferință la naștere, au fost alimentați natural, au primit profilaxia rahitismului și au fost vaccinați corect. Pacienții incluși în studiu au avut în istoric un minimum de 3 episoade de wheezing și un maximum de 10 episoade, media pentru toți pacienții fiind de aproximativ 4 episoade. Am analizat în continuare asocierea dintre anumiți factori de risc cunoscuți și severitatea episoadelor de wheezing, definită în cazul nostru prin prezența semnelor clinice de insuficiență respiratorie şi a hipoxiei și necesitatea administrării oxigenoterapiei. S-au calculat riscul relativ $(R R)$ și riscul atribuibil (RA) pentru fiecare factor de risc. In cadrul lotului studiat, cei mai importanți factori ce au influențat semificativ severitatea episoadelor de wheezing au fost prematuritatea, greutatea mică la naștere, mediul urban și prezența terenului atopic.

Concluzii. Copii cu teren atopic și multipli factori de risc necesită, cel mai probabil, tratament de control și o evaluare mai atentă, cu mențiunea că lipsa răspunsului la medicația antiastmatică necesită obligatoriu un diagnostic diferențial mai amplu. Mai mult de o treime dintre pacienți prezentau in antecedente peste 6 episoade de wheezing. Deși prezentau multiple episoade de wheezing, aceștia erau tratați doar intermitent pe perioade scurte de timp. Este nevoie, probabil, de o mai bună implementare a ghidurilor în practica curentă și de o reevaluare mai eficientă a cazurilor ce necesită tratament de control pentru a putea reduce severitatea episoadelor acute de wheezing și nevoia de spitalizare a acestora.
\end{abstract}

Cuvinte cheie: wheezing recurent, wheezing indus viral, astm bronșic 


\section{ABSTRACT}

Introduction. Recurrent wheezing represents a very common condition in the age group of 0-6 years. Several risk factors are associated with it, both genetic factors prenatal or postnatal environmental factors. It is important to evaluate to what extent these factors are involved in the occurrence of recurrent wheezing, but also how they influence the evolution of the disease.

Objective. The objective of the study was to evaluate the risk factors that influence the severity of acute wheezing episodes in children with recurrent wheezing.

Material and method. We conducted an observational prospective study that included 40 children aged 0-6 years with history of 3 or more wheezing episodes to demonstrate the existence of some epidemiological associations between certain risk factors and recurrent wheezing.

Results. The average age was approximately 22 months, the minimum age being 3 months, and the maximum age of 67 months. Of the 40 patients, $42.5 \%(n=17)$ experienced signs of acute respiratory failure at admission, these being patients with an increased severity of the acute wheezing episode.

Most of the children were born at term, breastfed, with correct vitamin D prophylaxis and complete immunization schedule. Patients enrolled in the study had a minimum of 3 episodes of wheezing and a maximum of 10 episodes in their history, the average for all patients being 4 episodes. We have further analyzed the association between certain known risk factors and the severity of wheezing episodes defined in our case by the presence of clinical signs of respiratory failure, hypoxia and the need for oxygen therapy. The relative risk (RR) and the attributable risk (AR) for each risk factor were calculated. Within the studied group, the most important factors that significantly influenced the severity of wheezing episodes were prematurity, low birth weight, urban environment and the presence of atopy.

Conclusions. Children with atopy and multiple risk factors most likely require more control and a more careful assessment the lack of response to antiasthmatic medication requires a careful differential diagnosis. More than one-third of the patients in the group had a history of over 6 episodes of wheezing. Although they had multiple wheezing episodes, they were only intermittently treated for short periods of time. Better implementation of guidelines in current practice and a more effective reevaluation of cases requiring long-term treatment is likely to be needed to reduce the severity of acute wheezing episodes and the need for hospitalization.

Keywords: recurrent wheezing, viral induced wheezing, asthma

\section{INTRODUCERE}

Wheezing-ul recurent este o afecţiune foarte frecvent întâlnită în grupa de vârstă 0-6 ani. El reprezintă o importantă problemă de sănătate, cele mai multe cazuri fiind asociate infecţiilor virale de tract respirator. Studiile arată că unul din trei copii experimentează minimum un episod de wheezing înainte de împlinirea vârstei de 3 ani. Termenul de wheezing recurent este folosit în practică pentru a defini cazurile ce au prezentat în antecedente cel puţin 3 episoade de wheezing. Etiologia acestei afecţiuni este multifactorială. Mai mulţi factori de risc sunt asociaţi cu wheezing-ul recurent, atât factori genetici, cât și factori de mediu prenatali sau postnatali. Este important de evaluat în ce măsură acești factori sunt implicaţi în apariţia wheezingului recurent, dar și cum influenţează ei evoluţia bolii (1-5).

\section{OBIECTIVE}

Obiectivul studiului a fost de a evalua prezenţa factorilor de risc ce influenţează severitatea episoadelor acute de wheezing la copii cu wheezing recurent. Evidenţierea acestor factori prezintă interes în vederea evitării expunerii individuale a copiilor, cu posibila reducere a morbidităţii și a ratei de spitalizare.

\section{MATERIAL ŞI METODĂ}

Am realizat un studiu observaţional, prospectiv, pentru a dovedi existenţa unora asocieri epidemiologice între anumiţi factori de risc și wheezingul recurent în rândul copiilor cu vârsta cuprinsă între 0 și 6 ani. Studiul a fost realizat pe un lot de 40 de copii din grupa de vârstă 0-6 ani cu cel puţin 3 episoade de wheezing în antecedentele personale patologice internaţi în Spitalului Clinic de Urgenţă pentru Copii „Grigore Alexandrescu“ în perioada 01.12.2017 - 31.05.2018. Prelucrarea datelor colectate din cele 40 chestionare s-a realizat cu ajutorul aplicaţiei Microsoft Excel Office 2016. Pentru analiza interrelaţională, s-a utilizat analiza bivariată a datelor continue cu ajutorul metodei Pearson și a celor categorice prin testul chi-square (chi pătrat), după realizarea tabelelor de contingenţă pentru fiecare categorie de date. 


\section{REZULTATE ŞI DISCUȚII}

\section{Analiza epidemiologică}

Lotul a cuprins 40 de copii, $60 \%$ au fost băieţi și $40 \%$ au fost fete. În literatura de specialitate, sexul masculin este citat ca factor de risc pentru apariţia wheezing-ului recurent (6). În lotul analizat, băieţii au reprezentat un procent mai important. Vârsta medie este de aproximativ 22 de luni, vârsta minimă fiind de 3 luni, iar cea maximă de 67 de luni.

TABELUL 1. Repartiţia pe grupe de vârstă

\begin{tabular}{|l|c|c|}
\hline Grupe de vârstă & Frecvența & Procent (\%) \\
\hline 3-6 luni & 10 & 25 \\
\hline 7-12 luni & 5 & 12,5 \\
\hline 13-18 luni & 8 & 20 \\
\hline 18-24 luni & 3 & 7,5 \\
\hline 25-36 luni & 3 & 7,5 \\
\hline 37-48 luni & 7 & 17,5 \\
\hline 49-60 luni & 3 & 7,5 \\
\hline 61-72 luni & 1 & 2,5 \\
\hline Total & 40 & 100 \\
\hline
\end{tabular}

\begin{tabular}{|l|r|}
\hline Mean & 21.9 \\
\hline Median & 16 \\
\hline Mode & 6 \\
\hline Minimum & 3 \\
\hline Maximum & 67 \\
\hline Count & 40 \\
\hline
\end{tabular}

Din totalul de pacienţi, $78 \%$ provin din mediul urban, un mediu cu un grad de ridicat de poluare a aerului, în care incidenţa bolilor de căi respiratorii superioare și inferioare la copii este mai mare (7), și numai $22 \%$ dintre pacienţi provin din mediul rural.

Dintre diagnosticele secundare asociate episodului de wheezing ne-am concentrat asupra cazurilor ce au asociat semne de insuficienţă respiratorie și saturaţie în oxigen sub 95\%. Dintre cei 40 de pacienţi, $42,5 \%$ ( $n=17$ ) au prezentat semne de insuficienţă respiratorie acută la internare, aceștia fiind pacienţii cu o severitate crescută a episodului acut de wheezing.

$80 \%$ dintre pacienţii din lotul de studiu au fost născuţi la termen $(n=32)$, iar restul de $20 \%$ sunt prematuri $(n=8) .82,5 \%$ din copii au prezentat un scor APGAR la naștere cuprins între 8 și $10(n=33)$, restul de $17,5 \%$ obţinând scoruri sub 8 . Analizând alimentaţia în perioada de sugar, lotul se distribuie astfel: $52,5 \%$ din numărul total de pacienţi au fost alimentaţi natural, 32,5\% au fost alimentaţi mixt și restul de $15 \%$ au fost alimentaţi artificial.

Din lotul de studiu, $90 \%$ dintre pacienţi au primit schema completă de vaccinare corespunzătoare vârstei $(n=36)$, iar $10 \%$ nu au primit-o din diverse motive invocate de aparţinători $(n=4)$. În ceea ce privește profilaxia rahitismului, $80 \%$ au primit corect schema de tratament cu vitamina $D$ $(n=32)$, iar 20\% ( $n=8)$ nu au primit. Carenţa de vitamina $D$ poate fi un factor de risc pentru apariţia wheezing-ului recurent (8).

După cum observăm în datele anamnestice, majoritatea copiilor au fost la termen, fără suferinţă la naștere, au fost alimentaţi natural, au primit profilaxia rahitismului și au fost vaccinaţi corect.

\section{Analiza factorilor de risc}

Pacienţii incluși în studiu au avut în istoric un minimum de 3 episoade de wheezing și un maximum de 10 episoade, media pentru toţi pacienţii fiind de aproximativ 4 episoade. 55\% dintre copii au prezentat câte 3 episoade de wheezing $(n=22)$, $25 \%$ au prezentat câte 4 sau 5 episoade $(n=10)$, restul de $20 \%$ din numărul total prezentând peste 6 episoade de wheezing $(n=8)$. Episoadele de wheezing sunt, de cele mai multe ori, asociate infecţiilor virale de căi respiratorii. Wheezing-ul cu triggeri multipli este mai rar întâlnit în practică la această grupă de vârstă, fiind însă acela ce asociază de multe ori și atopia. Acesta poate fi considerat în prezent un factor de risc și predictor pentru dezvoltarea astmului bronșic în copilărie $(4,9)$.

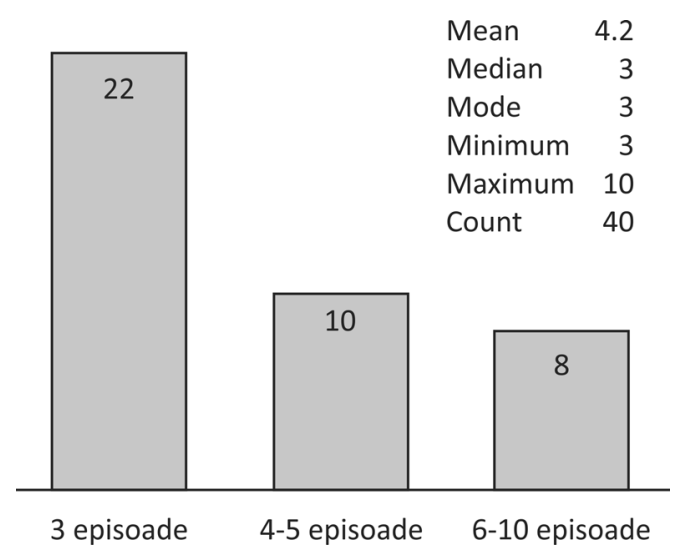

FIGURA 1. Distribuţia numărului de episoade de wheezing

Din numărul total de pacienţi, doar $37,5 \%$ au un istoric familial pozitiv pentru astmul bronșic ( $\mathrm{n}$ = 15), restul de 62,5\% negând prezenţa acestuia. Este important de cuantificat deoarece istoricul familial de alergii și astm bronșic în rândul rudelor de gradul 1 și 2 reprezintă factor de risc pentru apariţia wheezing-ului recurent (10). În ceea ce privește istoricul familial de alergii, doar $20 \%$ dintre aparţinătorii pacienţilor afirmă un istoric familial pozitiv $(n=8)$, restul de $80 \%$ susţinând un istoric familial de alergii negativ $(n=32)$.

Distribuţiile lotului în funcţie de istoricul personal de alergii și de dermatită atopică sunt aproxi- 
mativ similare. Din numărul total de pacienţi, $25 \%$ afirmă un istoric personal pozitiv pentru alergii (n = 10) și $27,5 \%$ pentru dermatita atopică $(n=11)$. Atât terenul atopic, alergiile manifeste, cât și dermatita atopică reprezintă factori de risc pentru dezvoltarea wheezing-ului recurent și factori predictori pentru astm $(11,12)$.

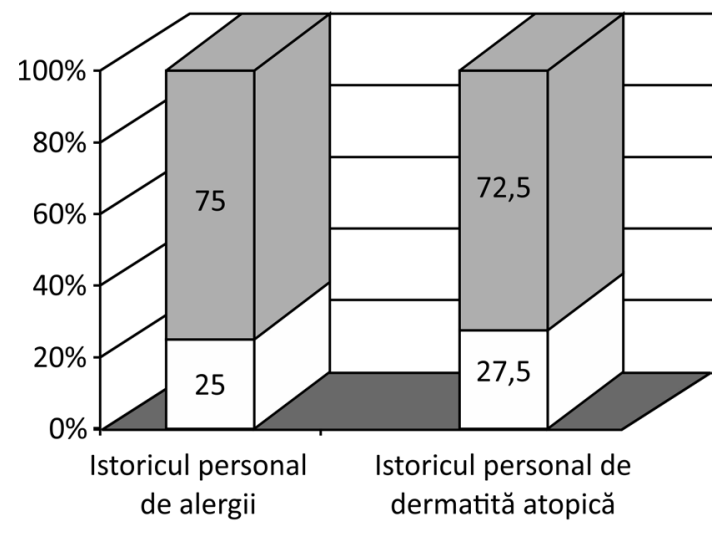

$\square$ Pozitiv $\square$ Negativ

FIGURA 2. Distribuţia pacienţilor în funcţie de istoricul de alergie şi dermatită atopică

Expunerea la mucegai în perioada de sugar reprezintă un alt factor cu o intensă corelaţie cu wheezing-ul recurent. În cadrul lotului de studiu, $37,5 \%$ dintre pacienţi au fost expuși la mucegai ( $n$ = 15) și 62,5\% neagă expunerea $(n=25)$.

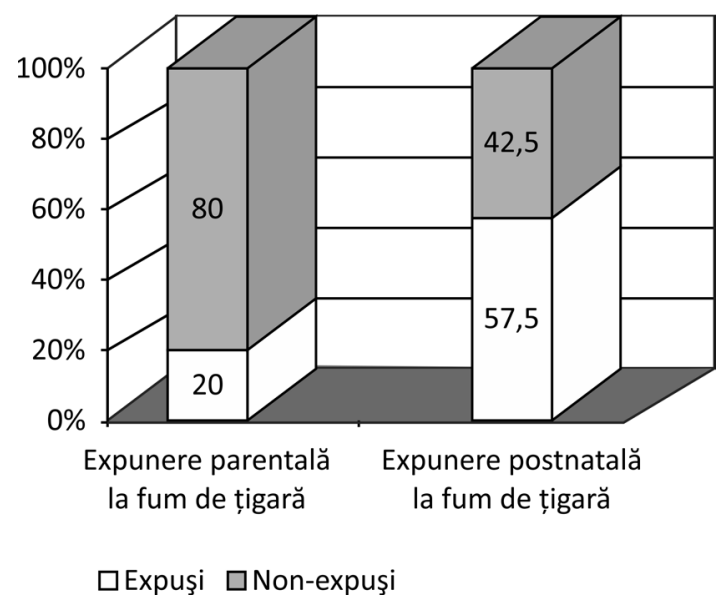

FIGURA 3. Distribuţia pacienţilor în funcţie de expunerea la fumul de ţigară

Expunerea la fumat în timpul sarcinii, la fel ca și expunerea postnatală la fumul de ţigară, poate reprezenta un factor de risc pentru apariţia episoadelor de wheezing recurent. Studiile sugerează că sugarii și copii mici expuși la fumul de ţigară prezintă episoade mai frecvente, mai severe și necesită spitalizare mai des (13-15). În cadrul lotului actual de studiu, 20\% dintre pacienţi provin din mame fumătoare pe parcursul sarcinii $(n=8)$ și $80 \%$ din mame nefumătoare pe parcursul sarcinii ( $n=32$ ). Situaţia este însă mai îngrijorătoare în ceea ce privește expunerea postnatală la fum de ţigară, deoarece peste jumătate dintre copii prezintă cel puţin un fumător în incinta locuinţei din rândul părinţilor sau bunicilor (57,5\% expuși la fum de tigară).

Expunerea la păr de animale în perioada de sugar reprezintă un alt factor de risc pentru wheezing-ul recurent, în special expunerea la păr de câini sau pisici (16). Din numărul total de 40 de pacienţi, 17 afirmă că au un animal de companie în casă sau în curte (reprezentând 42,5\% din totalul pacienţilor) și ceilalţi 23 neagă expunerea la păr de animale $(57,5 \%$ din numărul total de pacienţi).

\section{Analiza factorilor de risc asociați severității episodului acut}

Am analizat în continuare asocierea dintre anumiţi factori de risc cunoscuţi și severitatea episoadelor de wheezing, definite în cazul nostru prin prezenţa semnelor clinice de insuficienţă respiratorie și a hipoxiei și necesitatea administrării oxigenoterapiei. S-au calculat riscul relativ (RR) și riscul atribuibil (RA) pentru fiecare factor de risc.

Sexul a reprezentat un factor indiferent faţă de apariţia semnelor de insuficienţă respiratorie în cadrul unui episod acut de wheezing (RR $=1$ și RA $=0$ ). Tipul nașterii a reprezentat un factor indiferent pentru apariţia sindromului funcţional respirator în cadrul unui episod acut de wheezing. Prematuritatea reprezintă un factor de risc pentru apariţia semnelor de insuficienţă respiratorie în cadrul unui episod acut de wheezing ( $R R=1,47$ și $\mathrm{RA}=0,16)(17)$.

Greutatea mică la naștere reprezintă un factor de risc pentru apariţia sindromului funcţional respirator în cadrul unui episod acut de wheezing (RR $=1,42$ și RA =0,14). Aceasta asociază de obicei căi aeriene de calibru mai redus și se asociază cu apariţia wheezing-ului recurent (18).

Mediul de provenienţă urban reprezintă un factor de risc pentru apariţia unui episod sever de wheezing ( $R R=1,15$ și $R A=0,05)$.

Analizând factorii de mediu, rezultatele au fost următoarele: prezenţa alergiilor reprezintă un factor de risc pentru apariţia insuficienţei respiratorii în cadrul unui episod acut de wheezing ( $R R=1,66$ și RA $=0,2)$, la fel ca și prezenţa dermatitei atopice $(R R=1,32$ și $R A=0,11)$. Expunerea la păr de animale reprezintă factor de risc pentru apariţia unui episod sever de wheezing (19) $(\mathrm{RR}=1,2$ și $\mathrm{RA}=$ $0,07)$. 


\section{CONCLUZII}

Wheezing-ul recurent la copii mici și preșcolari reprezintă o problemă importantă de sănătate în practica pediatrică, în principal din cauza episoadelor acute severe ce necesită spitalizare. Există numeroși factori ce influenţează apariţia acestuia, frecvenţa și severitatea episoadelor și evoluţia către astm bronșic. În cadrul lotului studiat, cei mai importanţi factori ce au influențat semnificativ severitatea episoadelor de wheezing au fost prematuritatea, greutatea mică la naștere, mediul urban și prezenţa terenului atopic. Prezenţa terenului atopic și expunerea la alergenii din mediu influenţează și prognosticul pe termen lung al acestor cazuri, evoluţia acestora fiind, de cele mai multe ori, către astm bronșic. Acești copii cu teren atopic și multipli factori de risc necesită, cel mai probabil, tratament de control și o evaluare mai atentă, cu menţiunea că lipsa răspunsului la medicaţia antiastmatică necesită obligatoriu un diagnostic diferenţial mai amplu.
Mai mult de jumătate dintre copiii din lotul studiat erau expuși la fumul de ţigară, iar acesta poate influenţa atât frecvenţa, cât și severitatea episoadelor de wheezing. Informarea părinţilor este foarte importantă și ea trebuie făcută de către toţi medicii ce tratează copilul pentru că reducerea expunerii la fumul de ţigară poate reduce semnificativ atât numărul, cât și severitatea episoadelor de wheezing.

Mai mult de o treime dintre pacienţii din lotul studiat au prezentat un episod sever de wheezing, iar copii într-un procent asemănător prezentau în antecedente peste 6 episoade de wheezing. Deși prezentau multiple episoade de wheezing, aceștia erau trataţi doar intermitent pe perioade scurte de timp. Este nevoie, probabil, de o mai bună implementare a ghidurilor în practica curentă și de o reevaluare mai eficientă a cazurilor ce necesită tratament de control, pentru a putea reduce severitatea episoadelor acute de wheezing și nevoia de spitalizare a acestora.

Conflict of interest: none declared Financial support: none declared

\section{BIBLIOGRAFIE}

1. F Ducharme, SM Tse, BF Chauhan. Diagnosis, management, and prognosis of preschool wheeze. The Lancet, vol. 383, no. 9928, pp. 1593-1604, 2014

2. J Mallol, L Garcia-Marcos, D Solé, PLP Brand. International prevalence of recurrent wheezing during the first year of life: Variability, treatment patterns and use of health resources. Thorax, vol. 65 , no. 11 , pp. 1004-1009, 2010

3. C Stevens, D Turner, C Kuehni, J Couriel, M Silverman. The economic impact of preschool asthma and wheeze. European Respiratory Journal, vol. 21, no. 6, pp. 1000-1006, 2003

4. Castro-Rodriguez JA. The Asthma Predictive Index: A very useful tool for predicting asthma in young children. J Allergy Clin Immunol. 2010 Aug; 126(2):212-6.

5. Alvarez-Alvarez, Niu H, Guillen-Grima, Aguinaga-Ontoso. Meta-analysis of prevalence of wheezing and recurrent wheezing in infants. Allergol Immunopathol (Madr). 2016 Nov 16. p: S03010546(16)30122-7

6. Pérez-Yarza EG, Moreno-Galdó A, Ramilo et al. SAREPREM 3235 investigators. Risk factors for bronchiolitis, recurrent wheezing, and related hospitalization in preterm infants during the first year of life. Pediatr Allergy Immunol. 2015 Dec;26(8):797-804

7. Esposito S, Galeone C, Lelii M, Longhi B, Ascolese B, Senatore L, Prada E,
Montinaro V, Malerba S, Patria MF, Principi $\mathrm{N}$. Impact of air pollution on respiratory diseases in children with recurrent wheezing or asthma. BMC Pulm Med. 2014 Aug 7;14:130

8. Stenberg Hammar K, Hedlin G, Konradsen JR, Nordlund B, Kull I, Giske CG, Pedroletti $C$, Söderhäll C, Melén E. Subnormal levels of vitamin $D$ are associated with acute wheeze in young children. Acta Paediatr. 2014 Aug;103(8):856-61

9. Beigelman A, Bacharier LB. Management of preschool recurrent wheezing and asthma: A phenotype-based approach. Curr Opin Allergy Clin Immunol. 2017; 17(2):131-138

10. Beigelman A, Bacharier LB. Management of Preschool Children with Recurrent Wheezing: Lessons from the NHLBl's Asthma Research Networks. J Allergy Clin Immunol Pract. 2016;4(1):1-10.

11. Zhang Y, Zhou C, Liu J, Yang H, Zhao S. A new index to identify risk of multi-trigger wheezing in infants with first episode of wheezing. J Asthma. 2014 Dec; 51(10):1043-8

12. Sousa RB, Medeiros D, Sarinho E, Rizzo JÂ, Silva AR, Bianca AC. Risk factors for recurrent wheezing in infants: a casecontrol study. Rev Saude Publica. 2016; $50: 15$

13. Robison RG, Kumar R, Arguelles LM, Hong X, Wang G, Apollon S, Bonzagni A, Ortiz K, Pearson $\mathrm{C}$, Pongracic JA, Wang $\mathrm{X}$.
Maternal smoking during pregnancy, prematurity and recurrent wheezing in early childhood. Pediatr Pulmonol. 2012 Jul;47(7):666-73

14. Rosas-Salazar C, Hartert TV. Prenatal exposures and the development of childhood wheezing illnesses. Curr Opin Allergy Clin Immunol. 2017;17(2):110-115.

15. Schvartsman C, Farhat SC, Schvartsman $\mathrm{S}$, Saldiva PH. Parental smoking patterns and their association with wheezing in children. Clinics (Sao Paulo). 2013; 68(7):934-939.

16. Wazeka A., Valacer DJ, Cooper M, Caplan DW, DiMaio M. Impact of a pediatric asthma clinical pathway on hospital cost and length of stay. Pediatr Pulmonol. 2001 Sep; 32(3):211-6.

17. Ünal S, Kaya A, Bilgin L, Misirlioğlu E, Kocabaş CN. Wheezing, asthma, and atopy in premature infants at 2 years of age. Turk J Med Sci. 2017 Apr 18;47(2):607-613.

18. Vlad AM. Wheezing recurent la sugar şi copil mic.Etiologie şi factori de risc. Lucrare de licenţă. Bucureşti: UMF „Carol Davila”, Medicină; 2018.

19. Maria Cristina Ribeiro dos Santos Simões, Yuri Inoue, Natasha Y. Matsunaga, Maria R.V. Carvalho, Gisleine L.T. Ribeiro, Eliane O. Morais, Maria A.G.O. Ribeiro, André M. Morcillo, José D. Ribeiro, Adyléia A.D.C. Toro. Recurrent wheezing in preterm infants: Prevalence and risk factors, Jornal de Pediatria, July 2018 